\title{
Escrita acadêmica: por uma docência autoral
}

\author{
Academic Writing: for authoral teaching
}

\author{
Maria José Nélo \\ Nayara da Silva Queiroz ${ }^{2}$ \\ Gilvan Santos Gonçalves ${ }^{3}$
}

\begin{abstract}
RESUMO
Neste artigo, tem-se por relevância considerar as práticas de uma docência autoral, desde a formação acadêmica aos desdobramentos da aprendizagem de organização das ideias de que os diferentes textos atendam os detalhes e propósitos técnicos na formação de cidadãos e de sua autonomia acadêmica. Nesse sentido, é necessário fundamentar teoricamente de que maneira são ponderadas o ensino para a produção da escrita autoral, em particular, aqueles alunos que ingressam nos cursos de Letras. Dessa forma, a hipótese orientadora indica que o processo de ensino na educação básica ainda é incipiente para formação autoral na academia. Assim, os processos do uso dinâmico e complexo da linguagem devem ancorar as práticas de ensino da escrita autoral desde a educação básica, conforme proposições dos PCNs (1996, 1997, 1998). Na formação acadêmica, há orientações complementares realizados por Motta-Roth e Hendges (2010) sobre a importância e a necessidade de orientar a produção textual científica no meio acadêmico. Para tanto, concluímos que é preciso instruir os alunos para agir com autonomia leitora e escrita em diferentes contextos comunicativos na vida e no espaço acadêmico.
\end{abstract}

Palavras- chave: Ensino; Texto autoral; Escrita acadêmica.

\begin{abstract}
In this article, it is relevant to consider the practices of an author teaching, from the academic formation to the learning outcomes of the organization of ideas that different texts meet details and technical purposes in the formation of citizens and their academic autonomy. In this sense, it is necessary to theoretically substantiate how teaching is considered for the production of author writing, in particular, those students who enter the Letters courses. Thus, the guiding hypothesis indicates that the teaching process in basic education is still incipient for author writing training in academia. Thus, the processes of dynamic and complex use of language must anchor the teaching practices of author writing since basic education, as proposed by the PCNs (1996, 1997, 1998); and in the academic formation, there are complementary orientations made by Motta-Roth and Hendges (2010) on the importance and the need to guide the scientific textual production in the academic environment. Thus, we conclude that it is necessary to instruct students to act with reading and writing autonomy in different communicative contexts in life and in the academic space.
\end{abstract}

Keywords: Teaching; Author text; Academic writing.

\footnotetext{
${ }^{1}$ Doutora em Língua Portuguesa (área de concentração: Linguística) pela Pontifícia Universidade Católica de São Paulo (2011) e professora da Universidade Estadual do Maranhão (UEMA). E-mail: marianelo@uol.com.br

${ }^{2}$ Mestre em Ensino de Línguas pela Universidade do Vale do Taquari - UNIVATES/ RS. E-mail: nayaraqueiroz01@hotmail.com

${ }^{3}$ Graduado em Letras (Língua Portuguesa, Língua Espanhola e Respectivas Literaturas) pela Universidade Estadual do Maranhão (UEMA). (E-mail: gilvansantosg@outlook.com.br
} 


\section{Introdução}

Escrever é ter coisas para dizer

Darcy Ribeiro

O presente artigo visa refletir sobre os significados de uma docência autoral a partir da discussão de uma de suas vias de desdobramento: a escrita acadêmica.

Falar sobre autoria docente nos remete a ressignificação, a uma dinâmica constante que nos motiva a ser sujeitos autônomos e atuantes na condição de ser. $\mathrm{O}$ fazer docente se torna autoral na medida em que o professor cria estratégias que possibilitem discutir, refletir e analisar as práticas que promove em sala de aula e principalmente permitam que essas se constituam em condições necessárias para a promoção de uma aprendizagem significativa. Dessa forma, ao conceber que cada autor produz sua própria história, não podemos fechar a ideia de autoria, pois esta se constitui na materialização de experiências que, como uma grande colcha de retalhos, o autor costura por meio de sua imaginação.

Ao refinar a noção de autoria, como educadores, somos levados a (re)criar a docência a cada prática educativa, um compartilhamento de saberes e fazeres entre os sujeitos envolvidos no processo de ensino e aprendizagem. É importante concebermos a potência de criação de conhecimentos entre o contato que se tem entre o mundo exterior e o mundo particular do sujeito. Nesse ínterim, o saber ganha um espaço privilegiado no campo da própria experiência. Há uma liga- ção entre o mundo e o indivíduo, como afirma Larrosa (2002): "Eu creio no poder das palavras, na força das palavras, que fazemos coisas com as palavras e as palavras fazem coisas conosco.".

Nesse sentido, é válido relembrarmos que até o momento da entrada na educação formal, nossas conexões com os pares são feitas, sobretudo, por meios que nos são naturais, espontâneos e afetivos, porque são completamente ligados ao nosso ato de viver. A partir de então, entretanto, somos obrigados a embarcar em um mundo comunicativo em que as pessoas se expressam de formas aprendidas, que, por vezes, até nos prendem, mas com as quais o melhor é aprender a conviver, sem, no entanto, anular-se.

No contexto da educação básica, é interessante notar como um professor é convidado constantemente a imergir em um universo criativo, em um espaço de possibilidades de construção de autoria. A partir da articulação entre independência criadora do indivíduo que cria e dá sentido ao nosso universo de imaginação, materializamos nossas práticas por meio de relações significativas que ora sujeitos, ora assujeitados durante o processo de produção de saberes.

Assim, este artigo encontra-se estruturado em 4 seções, além de Introdução e Considerações finais. $\mathrm{Na}$ primeira seção, tratamos de discutir algumas proposições sobre a escrita acadêmica; Na segunda seção, algumas considerações sobre as bases legais da educação básica e dos cursos de licenciatura e finalmente a subseção 
que evidencia as competências e habilidades em Letras.

\section{Escrita acadêmica}

Traço linhas,

Linhas de escrita,

e a vida passa entre as linhas

Deleuze e Guattari (2015, p. 75)

Tendo como pano de fundo as palavras introdutórias da citação, iniciamos esta seção com intuito de considerar que a prática da escrita acadêmica perpassa pela docência autoral, ou seja, escrever um texto é antes de tudo despertar o interesse pela vida. É ser autor de sua história e senhor de suas ideias mesmo que saibamos que, como Foucambert (1994, p.76) evidencia em seus estudos, "escrever é inventar algo jamais lido, porém a partir de uma teoria já existente que tenta sistematizar todos os componentes que fazem parte da experiência de leitor de quem escreve". Assim, considerar as práticas de uma docência autoral desde a formação acadêmica aos desdobramentos da aprendizagem de organização das ideias é perceber que os diferentes textos precisam atender aos detalhes e aos propósitos técnicos na formação de cidadãos e de sua autonomia acadêmica.

Compreender a escrita em sua função social nos remete a outra prática muito importante para a concepção de um texto, a leitura. Dessa forma, vamos rememorar alguns conceitos que nos ajudarão a reforçar as competências e habilidades específicas de um sujeito como autor de um texto. Primeiramente evocamos Motta-Roth e Hendges (2010) quando destacam que o conceito de texto, etimologicamente, vem de tecer, tecido, trama organizada de fios. Um texto é uma trama escrita ou falada em que os fios são as ideias que são fruto de nossas experimentações com o mundo. Um texto é um tecido de ideias mediadas e relacionadas por meio da utilização da língua. Um texto é ainda

[...] um evento sociocomunicativo que existe dentro de um processo interacional. Ele é resultado de uma coprodução de interlocutores. $\mathrm{O}$ que distingue o texto escrito do falado é a forma como essa coprodução se realiza. (KOCH; ELIAS, 2010 p.13)

Somando-se a essa ideia, leitura significa compreender como está tecido o texto, constitui-se mais do que unir palavras e tentar fazer sentido. $\mathrm{O}$ universo da leitura de textos acadêmicos geralmente é um desafio para os estudantes que não estão familiarizados com leituras especializadas (artigos científicos, manuais, etc.) ou mesmo textos literários. Estes, quando ingressam na universidade, precisam se adaptar na maioria das vezes de maneira frustrante, por falta de intimidade leitora com os gêneros que circulam no meio acadêmico. Dessa forma, o estudante precisa aprender a lidar com o léxico científico, que apresenta conceitos que lhes parecem complexos e discursos elaborados em textos, exigindo, assim, concentração e dedicação de estudo.

O alinhamento das experiências de leitura e escrita na educação básica precisa esta relacionado a questões pontuais que compõem a tessitura superficial e profunda de um texto, como coerência e coesão textual. A interação 
com a escrita se dá de forma íntima entre sujeito-escritor e o campo de suas ideias e, quando é prazerosa, desperta no sujeito a escrita criativa, não mais aquela que lhe é alheia, enfadonha e não resultará em mais uma costura feita de recortes de textos diversos.

Nesse sentido, é necessário fundamentar teoricamente de que maneira são ponderadas o ensino para a produção da escrita autoral, em particular, aqueles alunos que ingressam nos cursos de Letras. Dessa forma, assumimos por hipótese orientadora que o processo de ensino na educação básica ainda é insipiente para formação autoral na academia. Os processos do uso dinâmico e complexo da linguagem devem ancorar as práticas de ensino da escrita autoral desde a educação básica, conforme espera-se que o aluno

[...] seja receptivo a textos que rompam com seu universo de expectativas, por meio de leituras desafiadoras para sua condição atual, apoiando-se em marcas formais do próprio texto ou em orientações oferecidas pelo professor; ( $\mathrm{PCN}$, 1998, p.49-50)

Cabe ainda sublinhar que, na formação básica, a prática da escrita ainda é vista com pouca clareza, sobretudo no que diz respeito a relevância do ensino da leitura a quem está aprendendo a escrever trabalhos acadêmicos. Num cenário como este, o jogo entre a leitura e a escrita está intimamente ligado a saberes institucionalizados nas estâncias de ensino nas escolas de educação básica e nas universidades.
$\mathrm{Na}$ formação acadêmica, há orientações complementares da importância e da necessidade de orientar a produção textual científica no meio acadêmico. A prática da escrita deve ser antecipada de uma leitura trabalhada que seja capaz durante o processo criativo identificar a autoria de quem está a redigir o texto, a sua identidade, a sua voz e a sua posição. Para tanto, concluímos que é preciso instruir os alunos para agir com autonomia leitora e escrita em diferentes contextos comunicativos na vida e no espaço acadêmico.

\section{Práticas de ensino da escrita autoral}

Revisitando nossas memórias, quando entramos na escola, nossos rabiscos nos papéis tão livres e com as cores da infância precisam ganhar outra forma e outra cor. Somos empurrados para um mundo onde nossa expressão mais válida é aquela que se apoia em algo exterior a nós, o papel. Daí para frente precisamos contrapor dois mundos: o eu e um outro; o da escrita e seus caminhos belos, mas, muitas vezes, obscuros. Em meio a este emaranhado de experimentações, como professores diante de uma docência criadora, concebemos o universo da escrita como campo aberto nas diversas áreas de conhecimento que, por meio de desenhos significativos, rabiscamos nossa história e memórias representativas com linhas dançantes que dão valor às nossas experimentações com o mundo que nos cerca. 
Diante do entrelaçamento do eu e o outro, é possível produzir uma escrita que se funde com o viver docente?

Tendo como pano de fundo a questão em evidência, é preciso afirmar que a escrita nos convida a embarcar em um mundo que nos permite criar diversas possibilidades de olhares e, como sujeitos subjetivos, concebemos a arte como uma via dialética que nos coloca frente a situações em que o eu se projeta para o outro por meio da escrita. A linguagem, nas suas mais diversas manifestações, veicula discursos a partir dos quais nos instauramos como sujeitos. Assim, em uma perspectiva docente autoral, é de se esperar que concebamos esse movimento como empoderador do sujeito e não assujeitador.

Experimentar processos inventivos e potencializadores da docência é estabelecer um diálogo entre o que ocorre nesse processo do escrever na academia e ainda o confrontamento da materialidade linguística que evidencia o sujeito e as normas desse contexto que dizem que não somos totalmente livre para nos expressar. O encontro do meu "eu" com o mundo acadêmico nos é posto como uma dor que perpassa por todo o corpo, carregada de aflições e inconstâncias de ideias que nos leva a incessantemente a nos perguntar se o que materializamos como discurso é de fato a nossa verdade efêmera.

Contrapondo o cenário laborioso, concebemos o processo criativo da escrita como algo não doloroso, sofrível, pelo contrário, pode-se firmar como um envolvimento permeado de exercício de pensamento aliado à afetividade. Um relacionamento no qual haja um mix de experimentações de tensão, (des)amor, gozo e até breves desilusões necessárias que nos levam a alacridade e constituem antes de tudo um contínuo de crescimento desprendido do já dito, dos estereótipos circundantes.

O docente, nesse panorama, representa um facilitador de enlace de mundos, da união da expressão da subjetividade de cada aluno com as especificidades da escrita. É salutar mostrar que, para ter valor científico, a linguagem não precisa obrigatoriamente despir-se de tudo aquilo que deixa transparecer um sujeito situado em um tempo e um contexto específicos resultante de marcas de uma jornada singular.

A busca por uma verdade una, homogênea, que muitas vezes subjaz às práticas acadêmicas é improdutiva, pois a realidade que conseguimos alcançar é sempre uma perspectiva. Como defende Nietzsche (2005), a verdade é uma "multiplicidade incessante de metáforas, de metonímias, de antropomorfismos, em síntese, uma soma de relações humanas que foram poética e retoricamente elevadas, transpostas, ornamentadas". Como docentes autorais, é importante considerarmos que as marcas de subjetividade na escrita de nossos alunos revelam uma forma peculiar de observar determinado fenômeno a partir do compartilhamento com outros olhares.

\section{Bases legais}

Realizar uma discussão sobre a formação docente e suas bases legais requer que se faça uma breve análise 
dos Projetos Pedagógicos dos Cursos de Letras Licenciatura em Língua Portuguesa, Língua Inglesa e Literaturas, pois a atenção ao papel da educação como elemento nodal do desenvolvimento social e humano aproximam-se das necessidades à inserção no processo produtivo. As transformações proporcionadas pelas tecnologias da informação e comunicação é uma das possibilidades de repensar uma sociedade, decorrente da revolução tecnológica e seus desdobramentos na produção e na área da informação, sem perder de vista os princípios definidos na atual Lei de Diretrizes e Bases, que estabelece que os processos de ensino e aprendizagem devam basear-se no desenvolvimento de competências e habilidades, voltados para os verdadeiros interesses da sociedade maranhense e brasileira.

Compreendendo a proposta dos cursos de licenciatura em Letras das Universidades públicas do Maranhão, é mister verificar se as instâncias de ensino superior ensinam a gramática em detrimento do ensino da língua em seus mais variados contextos e ou condições de uso. Assim, concebemos que os Parâmetros e a Base Curricular Comum são documentos oficiais que fomentam a Lei de Diretriz e Base buscam equacionar as desigualdades sociais brasileiras.

\section{Lei de Diretrizes e Bases da Educação Nacional (Lei $\mathbf{N}^{\mathbf{0}}$ 9.394/1996)}

Art. 62. A formação de docentes para atuar na educação básica far-se-á em nível superior, em curso de licenciatura, de graduação plena, em universidades e institutos superiores de educação, admitida, como formação mínima para o exercício do magistério na educação infantil e nas quatro primeiras séries do ensino fundamental, a oferecida em nível médio, na modalidade Normal.

Essa regulação tem caráter basilar e determina que a formação docente para o exercício do magistério da educação básica se dará em licenciaturas de graduação plena. Ao estabelecer a formação em nível superior nos cursos de licenciatura como condição sine qua non para a formação docente, a LDB representa um avanço em relação aos modelos anteriores, onde essa formação era um plus ou um apêndice dos bacharelados.

XI. Portaria Normativa $n^{\circ} 40$, de 12 de dezembro de 2007, que institui o e-MEC, sistema eletrônico de fluxo de trabalho e gerenciamento de informações relativas aos processos de regulação, avaliação e supervisão da educação superior no sistema de educação, e o Cadastro e-MEC de Instituições e Cursos Superiores e consolida disposições sobre indicadores de qualidade, banco de avaliadores (Basis) e o Exame Nacional de Desempenho dos Estudantes (ENADE) e outras disposições

A partir desta portaria, a tramitação dos processos de regulação, avaliação e supervisão de instituições e cursos de educação superior será feita exclusivamente em meio eletrônico, no sistema e-MEC:

XII. Decreto $\mathrm{N}^{\circ}$ 6.755, 29 de maio de 2009, que institui a Política Nacional de Formação de Profissionais do Magistério da Educação Básica, 
disciplina a atuação da Coordenação de Aperfeiçoamento de Pessoal de Nível Superior(CAPES) no fomento a programas de formação inicial e continuada, e dá outras providências.

O referido Decreto expressa uma alteração significativa no cenário da definição das políticas voltadas para a formação de professores no Brasil ao institucionalizar uma política nacional para essa área. A explicitação dessa política se dá em um contexto de reformulação de um projeto nacional para a educação brasileira, vide as discussões produzidas no âmbito da Conferência Nacional de Educação (CONAE) e a tramitação no Congresso Nacional do projeto de lei que cria o Plano Nacional de Educação para a próxima década.

Entre os princípios instituídos pelo Decreto (Art. $2^{\circ}$ ) cumpre destacar a garantia de padrão de qualidade dos cursos de formação de docentes ofertados pelas instituições formadoras nas modalidades presencial e à distância (IV); a articulação entre a teoria e a prática no processo de formação docente, fundada no domínio de conhecimentos científicos e didáticos, contemplando a indissociabilidade entre ensino, pesquisa e extensão (V); e a importância do projeto formativo nas instituições de ensino superior que reflita a especificidade da formação docente, assegurando organicidade ao trabalho das diferentes unidades que concorrem para essa formação e garantindo sólida base teórica e interdisciplinar (VII).
Diante disso, convém refletir sobre a importância que é dada às políticas de formação docente que contribuem para o fazer docente. Os Parâmetros Curriculares Nacionais -PCN apontam orientações ao professor questões de ordem metodológica que tanto contribuem para a prática de ensino e, ainda nessa mesma direção, a BNCC complementa com uma possível busca para basilar ou ainda na tentativa de unificar os currículos educacionais.

Dessa forma, é necessário que os Cursos de Letras Licenciatura repensem esse papel da educação, a partir de uma nova proposta curricular, que considere organização de atividades e ações que possam desenvolver habilidades cognitivas e competências sociais por meio do conhecimento com vistas a atuação desse futuro profissional no mercado de trabalho, ou seja, atuante na educação básica.

\section{Competências e habilidades em Letras}

De acordo com a LDB e o Parecer do CNE/CES no 492/01, o graduado em Letras, tanto em língua materna quanto em língua estrangeira clássica ou moderna, nas modalidades de bacharelado e de licenciatura, deverá ser identificado por múltiplas competências e habilidades adquiridas durante sua formação acadêmica convencional, teórica e prática, ou fora dela.

Nesse sentido, visando à formação de profissionais que demandem o domínio da língua estudada e suas culturas para atuar como professores, 
pesquisadores, críticos literários, tradutores, intérpretes, revisores de textos, roteiristas, secretários, assessores culturais, entre outras atividades, o curso de Letras deve contribuir para o desenvolvimento das seguintes competências e habilidades:

Figura 1 - Competências e habilidades do docente em Letras

\section{Competências e Habilidades}

- Domínio do uso da língua portuguesa ou de uma língua estrangeira, nas suas manifestações oral e escrita, em termos de recepção e produção de textos;

- Reflexão analítica e crítica sobre a linguagem como fenômeno psicológico, educacional, social, histórico, cultural, político e ideológico;

- Visão crítica das perspectivas teóricas adotadas nas investigações linguísticas e literárias, que fundamentam sua formação profissional;

- Preparação profissional atualizada, de acordo com a dinâmica do mercado de trabalho;

- Percepção de diferentes contextos interculturais;

- Utilização dos recursos da informática

- Domínio dos conteúdos básicos que são objeto dos processos de ensino e aprendizagem no ensino fundamental e médio;

- Domínio dos métodos e técnicas pedagógicas que permitam a transposição dos conhecimentos para os diferentes níveis de ensino

Fonte autoral

Diante desse universo de competências e habilidades, o egresso do Curso de Letras é um profissional com conhecimento diferenciado, contemporâneo e instigante, dentro de uma visão crítica. Sua formação privilegia a competência para vasto campo de atuação. Tem domínio de tecnologia avançada e experiência em aprendizagem que articula ensino, pesquisa e extensão, o que o prepara para exercer com competência sua profissão.

Considerando uma proposta que contemple as especificidades de um graduado em Letras de língua materna e de língua estrangeira, entendese que o planejamento é ponto crucial para a formação de profissionais que, conscientes da sua função social, desempenharão habilidades de reflexão e crítica, tornando-os agentes transformadores de seu meio.

Assim, contrastando este cenário que versa o sistema acadêmico universitário brasileiro, é comum nos depararmos com a pressão que a sociedade letrada nos faz a mergulhar no universo da prática da escrita, por considerar que o profissional em Letras tem intimidade com a elaboração de textos de qualidade teórica-prática. Dentro do processo de escrever um texto, estão o escritor e seu conhecimento de mundo, fruto de experiências de leituras que se materialização em escrita. Nesse caminho, é conveniente ressaltar a máxima "[...] Primeiro, a leitura do mundo; depois, a leitura das palavras, para atribuir-lhes valor" (GUEDES, 2009, p.17). Corroborando 
com o autor, finalizamos esta seção evidenciando que o mundo está antes e depois do texto, ou seja, a construção da tessitura de um texto é resultado de experimentações de mundo.

\section{Considerações finais}

Não intentamos fazer deste texto prescritivo. Não se constitui ainda como uma receita em que docentes e estudantes possam se apoiar para construir seus textos nos ambientes educacionais. Procuramos apenas suscitar algumas reflexões que são necessárias aos sujeitos leitores e escritores ou mesmo aqueles que pretendem adentrar nesse universo da redação acadêmica.

A cada leitura, descortinamos uma ideia que, ao se encontrar com nosso conhecimento de mundo, trazemos à tona por meio da fala oralizada ou da escrita. Assim, escrever de forma criativa talvez seja expressar ideias de maneira autoral, sem a mesmice do lugar de conforto. Mesmo que o assunto seja algo que foi bastante explorado por outros escritores, podem ser retratados de forma criativa. Por outro lado, sem a devida dedicação e cuidado, nossa escrita será só mais uma entre tantas outras que se assemelham por temática.

Ser um docente autoral, é, pois, despertar nos estudantes o sabor e o prazer de ser autoral no seu fazer, seja na sua forma de leitura ou de escrever. Trata-se de fazer do seu jeito, mas com o cuidado e esmero que a escrita acadêmica merece. Mas... uma docência autoral precisa nascer na prática, na base, nas escolas desde o processo de letramento de construção das habilidades de leitura e escrita.

Diante do exposto, este artigo buscou no âmbito da experiência docente promover experimentações que problematizam a arte da escrita acadêmica com vistas em reflexões sobre o ensino da produção textual na universidade aos estudantes como sujeitos ativos que precisam tentar resistir, como afirma Larrosa (2002): “[...] lutar pelas palavras, significado, domínio, pela imposição de certas palavras e ainda pelo silenciamento de ideias que transbordam o esperado [...]". É premente retecer as ideias do fazer acadêmico, muitas vezes castrador pela via da linguagem, com vistas a uma docência criadora que promova as microrrevoluções possíveis e defenda a ideia de que também constitui um empoderamento utilizar uma linguagem que evidencie sujeitos ativos, abertos a práticas educativas facilitadoras do processo de ensino e aprendizagem, em que haja um reconhecimento das subjetividades. 


\section{Referências}

ANTUNES, Irandé. Língua, Texto e Ensino: outra escola possível. São Paulo: Parábola Editorial, 2009.

BRASIL. Lei de Diretrizes e Bases da Educação Nacional. Lei número 9394, 20 de dezembro de $1996 . \quad$ Disponível em: http://www.planalto.gov.br/ccivil_03/LEIS/L9394 .htm. Acesso em: 15 abril 2019.

BRASIL. Ministério da Educação. MEC- Parecer do CNE/CES n40/07. Disponível em: http://portal.mec.gov.br/cne/arquivos/pdf/CES0492.pdf. Acesso em: 17 abril. 2019.

BRASIL. Ministério da Educação. Presidência da República. Decreto Nº 6.755, 29 de maio de 2009. Dispõe sobre o exercício das funções de regulação, supervisão e avaliação de instituições de educação superior e cursos superiores de graduação e sequenciais no sistema federal de ensino. Brasilia (DF), 2006.

BRASIL. SECRETARIA DA EDUCAÇÃO FUNDAMENTAL. Parâmetros Curriculares Nacionais - 3oe 4ociclos do ensino fundamental. Língua Portuguesa. Brasília: MEC/SEF, 1998.

BAZERMAN, Charles. Retórica da ação Letrada. Tradução. 1 ed. São Paulo: Parábola Editorial, 2015.

FOUCAMBERT, Jean. A leitura em questão. Trad. Bruno Charles Magne. Porto Alegre. Artes Médicas, 1994.

GUEDES, Paulo Coimbra. Da redação à Produção Textual: o ensino da escrita. São Paulo: Parábola Editorial, 2009.

KOCH, Ingedore Villaça; ELIAS, Vanda Maria. Ler e compreender: os sentidos do texto. 3. ed. São Paulo: Contexto, 2010.

LIMA, Vladimir Moreira. \& nbsp Deleuze - Guattari e a Ressonância mútua entre filosofia e política. $1^{\text {a }}$ ed. Rio de Janeiro: Ed. Ponteiro, 2015.

LARROSA, Jorge. Notas sobre a experiência e o saber de experiência. Revista Brasileira de educação No 19, 2002. 
MOTTA-ROTH, Désirée; HENDGES, Graciela. Produção textual na Universidade. São Paulo: Parábola Editorial, 2010.

NIETZSCHE, F. Introdução Teorética sobre a Verdade e a Mentira no Sentido Extramoral. In: O Livro do Filósofo. 6ª ed. São Paulo: Centauro, 2005.

$O(s)$ autor(es) se responsabiliza(m) pelo conteúdo e opiniões expressos no presente artigo, além disso declara(m) que a pesquisa é original.

Recebido em 10/03/2020

Aprovado em 20/06/2020 